REVIEW

\title{
Insulin resistance as a contributor to myocardial ischaemia independent of obstructive coronary atheroma: a role for insulin sensitisation?
}

\author{
S Jadhav, J Petrie, W Ferrell, S Cobbe, N Sattar
}

Heart 2004;90:1379-1383. doi: 10.1136/hrt.2004.035170

There is good evidence to suggest that insulin resistance and its surrogate markers are at least modest independent cardiovascular risk factors. However, as well as long term effects on atheromatous coronary disease, there is a well described correlation between markers of insulin resistance and endothelial dysfunction. In this review, the evidence for a relation between endothelial dysfunction and myocardial ischaemia is summarised. The evidence for a correlation between insulin resistance and endothelial dysfunction and the proposed cellular mechanisms are also examined.

Finally, the potential role for insulin sensitising strategies is looked at and recent data examining their effects on both endothelial function and clinical symptoms is examined. In conclusion, it was found that insulin sensitising modalities have a potential role in the amelioration of angina and that randomised controlled studies are therefore warranted.

See end of article for authors' affiliations

Correspondence to: Dr Sachin Jadhav, Department of Medical Cardiology, Glasgow Royal Infirmary, Glasgow G31 2ER, UK; stjadhav@ bigfoot.com

Accepted 24 May 2004
M yocardial ischaemia is a common cause of morbidity and mortality. Essentially, ischaemia occurs when the blood supply to the myocardium is too poor for its metabolic demands to be met. The end artery nature of the coronary circulation, with a relative lack of anastomosis between the major coronary arteries, makes the condition more prevalent in myocardium. When the myocardial metabolic demands, in particular for oxygen, are not met, anaerobic metabolism manifests, with production of lactate, leading to symptomatic angina. At its most serious, myocytes that remain ischaemic beyond a critical time period die, resulting in myocardial infarction.

The importance of type 2 diabetes mellitus is well established as a cardiovascular risk factor. The cardiovascular risk of patients with insulin resistance, with or without glucose intolerance, has become apparent as described in a recent meta-analysis, looking at hyperinsulinaemia as a surrogate marker. ${ }^{1}$ Reaven described the forerunner of what has become known as insulin resistance syndrome (also called metabolic syndrome X) in 1988. Since then, the definitions have been extended such that a cluster of interrelated cardiovascular risk factors including central adiposity, hypertension, dyslipidaemia, and disturbances of fibrinolysis, with abnormalities of insulin metabolism at the core, are now described. ${ }^{2}$
Here we collate available evidence to suggest that insulin resistance, in addition to promoting physical obstructive atheromatous coronary disease, may lead to myocardial ischaemia via the process of endothelial dysfunction. Based on these observations, we suggest that amelioration of insulin resistance, whether by established or novel mechanisms, may at least in part restore normal endothelial function and potentially ameliorate anginal symptoms.

\section{Evidence for endothelial dysfunction as a causative factor in angina independent of obstructive disease}

In conventional angina there is evidence to suggest that endothelial function in the myocardial vascular bed is abnormal. Coronary atherosclerosis is associated with a reduced vasodilator response and a paradoxical vasoconstrictor response to acetylcholine. This has been shown in response to both atrial pacing and bicycle exercise during coronary angiography and these functional abnormalities may contribute to ischaemia in patients with obstructive coronary disease. ${ }^{3-5}$ However, it is difficult to implicate this as a direct cause of ischaemia caused by coexisting flow limiting atheroma.

A subgroup of patients with angina has normal coronary arteries despite evidence of ischaemia demonstrated using non-invasive methods. This defines the group termed to have microvascular angina. There is good evidence to support the notion that these patients also have impaired microvascular function mediated by abnormal endothelial vasomotor responses and that this could potentially be an aetiological factor in ischaemia. Impaired endothelial function has been demonstrated in subjects with "cardiac syndrome $X^{\prime}$, using methods including brachial artery flow mediated dilatation ${ }^{67}$ and abnormal coronary vascular responses assessed by intracoronary Doppler. ${ }^{8}$ In fact, recent data published in abstract form support a correlation between levels of endothelial dysfunction and ST segment depression as a marker for ischaemia in such women. ${ }^{10}$

It is postulated that this impairment of endothelial function results in failure of the normal coronary vasodilatory response at times of stress, such that the arterial supply does not match the enhanced demand, leading to the activation of anaerobic metabolism and

Abbreviations: NO, nitric oxide; PI3-kinase, phosphatidylinositol 3-kinase 


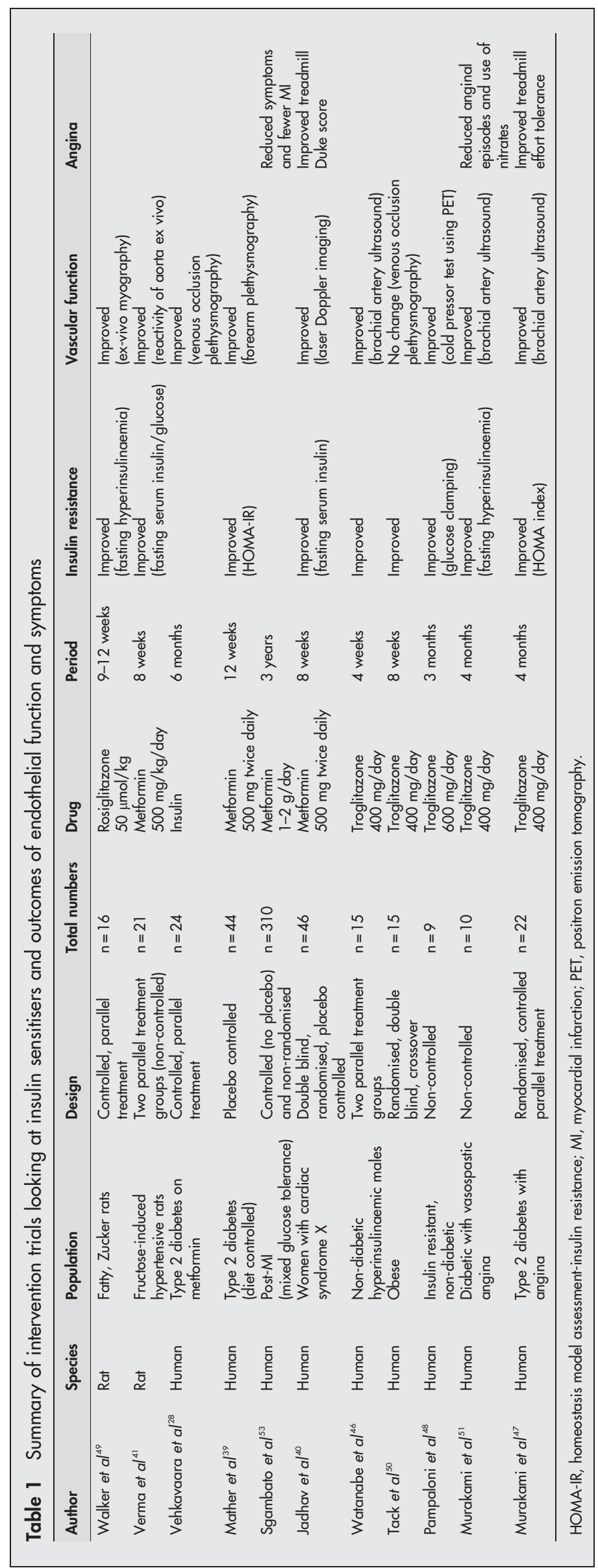




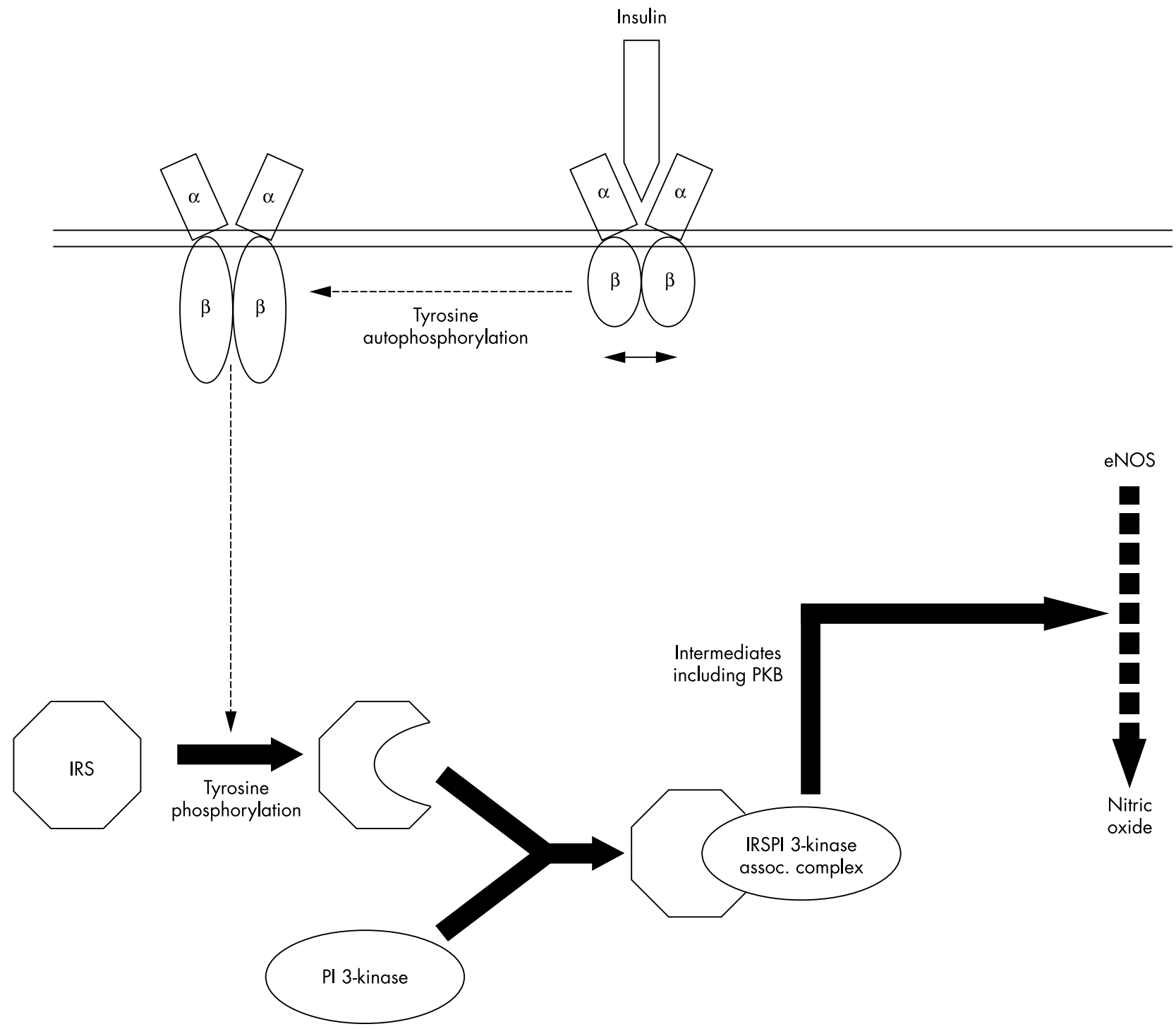

Figure 1 Schematic outlining insulin receptor and nitric oxide production coupling in endothelium. eNOS, endothelial nitric oxide synthase; IRS, insulin receptor substrate; PI 3-kinase, phoshatidylinositol 3-kinase; PKB, protein kinase B.

ischaemic pain. This group of patients provides an opportunity to study functional vessel abnormalities in the absence of obstructive atheroma.

\section{Link between insulin resistance and endothelial dysfunction}

Insulin resistance, as well as being the precursor for type 2 diabetes, has several pleiotrophic effects. These include several of the features of the metabolic syndrome including dyslipidaemia, as well as direct promotion of atheroma production.

Another such effect is its influence on vascular function. Impaired endothelial function in type 2 diabetes has been shown using venous occlusion plethysmography, ${ }^{11}{ }^{12}$ high resolution brachial artery ultrasound, ${ }^{13}$ and more recently by laser Doppler imaging. ${ }^{14}$ In addition, Balletshofer et al have shown that clamp derived indices of insulin resistance correlate with endothelial responses in first degree relatives of subjects with type 2 diabetes, using brachial artery ultrasound..$^{15}$ Similarly, Jaap et al described an association between insulin sensitivity and microvascular function in non-diabetic subjects with fasting hyperglycaemia, using laser Doppler fluximetry in response to local heating. ${ }^{16}$ Serne et al extended these observations by demonstrating that microvascular function as assessed by laser Doppler flowimetry is associated with insulin sensitivity even in normal subjects. ${ }^{17}$ Furthermore, in a study of the coronary circulation in subjects with unobstructed coronaries, a strong correlation between clamp derived indices of insulin resistance and coronary vascular function assessed by Doppler blood flow recordings was noted..$^{18}$

Other aspects of the insulin resistance syndrome have been associated with endothelial dysfunction. Obese individuals without diabetes have endothelial dysfunction both in the peripheral and coronary circulation, ${ }^{19}$ and a specific link to central adiposity has been noted by some. ${ }^{20}$ Steinberg et al showed blunted leg blood flow in response to arterial infusions of methacholine in obese, insulin resistant subjects compared to controls. Importantly, whereas the production of euglycaemic hyperinsulinaemia augmented blood flow in lean subjects, this response was not apparent in obese. ${ }^{21}$ Endothelial dysfunction has also been documented in in vivo and ex vivo experiments in subjects with hypertension, and in association with dyslipidaemia, particularly in those subjects with high triglycerides and low high density lipoprotein (HDL) cholesterol. ${ }^{22-24}$ 
A close correlation between insulin sensitivity and endothelial nitric oxide (NO) synthesis is seen in healthy volunteers. ${ }^{25} \mathrm{~A}$ similar correlation is seen between insulin sensitivity and vasoconstrictor responses to N-monomethylL-arginine, a NO inhibitor, in a mixed group of men including patients with diabetes, hypertension, and healthy volunteers. $^{26}$ Furthermore, the vasodilatory effect of insulin is amplified in the presence of metabolically active glucose in healthy subjects. ${ }^{27}$ This observation, together with findings that insulin augments blood flow in lean subjects, points towards a key role for insulin and glucose metabolism in maintaining vasodilator tone in vessels via NO. This is supported by the observation that exogenous insulin treatment appears to improve endothelial function in patients with type 2 diabetes. ${ }^{28}$

The post-receptor signalling mediators involved in the production of NO in response to insulin in many ways parallel those which regulate insulin mediated glucose transport via GLUT4 translocation (fig 1). It appears that activation of phosphatidylinositol 3-kinase (PI3-kinase) is crucial in this signalling pathway. Cells expressing an inhibitory mutant of PI3-kinase have a much attenuated NO response to insulin. Downstream mediators of this effect may include protein kinase B (PKB) also known as Akt, ${ }^{29}$ possibly by phosphorylating endothelial nitric oxide synthase (eNOS).$^{30}$ However, other pathways may also be involved and remain to be characterised. In particular, intracellular $\mathrm{Ca}^{+2}$ concentrations are affected by insulin, mainly by stimulation of the $\mathrm{Na}^{+}-\mathrm{H}^{+}$exchanger and $\mathrm{Na}^{+}-\mathrm{K}^{+}$ATPase and therefore insulin resistance may have a direct $\mathrm{Ca}^{+2}$ mediated influence on vascular tone. ${ }^{31}$

\section{Microvascular angina, insulin resistance, and endothelial dysfunction}

In parallel with the above observations, several groups have demonstrated relative insulin resistance in post-menopausal women and non-obese men with microvascular angina, together with lipid perturbances and higher blood pressure. ${ }^{32-36}$

Furthermore, there are data to suggest that subjects with microvascular angina have a reduced whole body NO response to insulin. ${ }^{37}$ This leads to the hypothesis that resistance to this effect of insulin could manifest in impaired endothelial function via intermediates including NO.

\section{Can improving insulin resistance improve endothelial function?}

While the above observations are compelling, proving a causal relation between insulin action and endothelial function requires interventional studies. Very recent uncontrolled data show that intentional weight loss by means of a hypocaloric diet combined with exercise, and in some cases surgical liposuction, improves endothelial vasomotor function as measured by haemodynamic responses to intravenous L-arginine (a NO precursor). ${ }^{38}$ This improvement coincided with reduction in fasting insulin and cytokine concentrations.

Metformin, the only biguanide in clinical use, has been available in the UK for over 30 years. Its exact mechanism of action remains unclear but it is thought to involve increasing tyrosine kinase activity in the insulin receptor with intracellular effects mediated via the PI3-kinase pathway on GLUT4 translocation as well as NO production (fig 1).

One 12 week trial of metformin compared to placebo in individuals with type 2 diabetes showed improved endothelial function as measured by forearm plethysmography, in the metformin group alone. ${ }^{39}$ Data recently published in abstract form reported significant improvements in endothelial dependant microvascular function, in a group of women with cardiac syndrome $X$, following eight weeks of metformin treatment compared with placebo. ${ }^{40}$ These observations concur with preliminary animal data where chronic metformin treatment improved aortic vascular properties in hyperinsulinaemic, fructose induced hypertensive rats. ${ }^{41}$ Metformin has other complex intracellular actions, one of which is activation of adenyl monophosphate kinase (AMPkinase) ${ }^{42}$ which in turn has been shown to directly activate NO synthase. ${ }^{43}$ This mechanism in itself may contribute to the vasoactive effects of metformin independently of its action on insulin metabolism.

Modest weight loss during metformin treatment is well described $^{44}$ and thus it is difficult to dissect whether vascular effects are solely because of this. By contrast, thiazolidinediones improve insulin sensitivity without reducing weight, with redistribution of adipose tissue from visceral to subcutaneous deposits. ${ }^{45}$ Troglitazone has been reported to improve endothelial function measured by flow mediated brachial artery diameter, after either four weeks ${ }^{46}$ or four months of treatment. ${ }^{47}$ Preliminary data have extended these findings to include an improvement in myocardial blood flow, measured non-invasively using positron emission tomography, in nondiabetic insulin resistant individuals after three months of troglitazone treatment. ${ }^{48}$ In animal models, rosiglitazone improved indices of insulin resistance and myography based measures of vascular function in fatty Zucker rats. ${ }^{49}$ There is one report, however, showing a lack of effect of troglitazone on vascular function assessed by plethysmography. ${ }^{50}$

\section{Can improving insulin resistance lessen anginal frequency?}

Preliminary data suggests that in diabetic patients with angina, four months treatment with troglitazone not only improves endothelial function, as assessed by brachial artery ultrasound, but also treadmill exercise capacity. ${ }^{47}$ In a study published so far only in abstract form, troglitazone has also had beneficial effects on both the frequency of chest pain, and measures of endothelial function, in vasospastic angina, ${ }^{51}$ which is associated with insulin resistance and abnormal vascular function. ${ }^{52}$ Another study, also only in abstract form so far, demonstrated improved Duke score ischaemic measures in women with cardiac syndrome $\mathrm{X}$ following metformin administration..$^{40}$ Finally, a non-randomised study of metformin, given post-myocardial infarction, to a large group of patients with varying glucose tolerance, suggested a significant lessening of anginal symptoms and fewer new infarcts in those who received metformin compared to those who did not..$^{53}$

\section{CONCLUSION}

Prospective data have established markers of insulin resistance as an independent cardiovascular risk factor. We have suggested that insulin resistance is implicated in the pathogenesis of endothelial dysfunction, and therefore via this route, myocardial ischaemia. Indeed, there is tantalising evidence to show that insulin sensitisers may improve not only insulin resistance and endothelial function, but also anginal symptoms and exercise capacity in diverse patient groups. We suggest, therefore, that further properly randomised studies are required to elaborate the potential of insulin sensitising agents in the treatment of angina.

\section{ACKNOWLEDGEMENTS}

Funding for the research fellowship supporting Dr Sachin Jadhav is provided by the British Heart Foundation.

\section{Authors' affiliations}

S Jadhav, S Cobbe, Department of Medical Cardiology, Glasgow Royal Infirmary, Glasgow, UK

J Petrie, W Ferrell, Department of Medicine, Glasgow Royal Infirmary N Sattar, Department of Pathological Biochemistry, Glasgow Royal Infirmary 


\section{REFERENCES}

1 Ruige JB, Assendelff WJ, Dekker JM, et al. Insulin and risk of cardiovascular disease: a meta-analysis. Circulation 1998;97:996-1001.

2 Reaven GM. Role of insulin resistance in human disease (syndrome X): an expanded definition. Annu Rev Med 1993;44:121-31.

3 Gage JE, Hess OM, Murakami T, et al. Vasoconstriction of stenotic coronary arteries during dynamic exercise in patients with classic angina pectoris: reversibility by nitroglycerin. Circulation 1986;73:865-76.

4 Gordon JB, Ganz P, Nabel EG, et al. Atherosclerosis influences the vasomotor response of epicardial coronary arteries to exercise. J Clin Invest 1989:83:1946-52.

5 Nabel EG, Selwyn AP, Ganz P. Paradoxical narrowing of atherosclerotic coronary arteries induced by increases in heart rate. Circulation 1990;81:850-9.

6 Botker HE, Sonne HS, Sorensen KE. Frequency of systemic microvascular dysfunction in syndrome $\mathrm{X}$ and in variant angina. Am J Cardiol 1996; 78:182-6.

7 Lekakis JP, Papamichael CM, Vemmos CN, et al. Peripheral vascular endothelial dysfunction in patients with angina pectoris and normal coronary arteriograms. J Am Coll Cardiol 1998:31:541-6.

8 Chauhan A, Mullins PA, Taylor G, et al. Both endothelium-dependent and endothelium-independent function is impaired in patients with angina pectoris and normal coronary angiograms. Eur Heart $J$ 1997; 18:60-8.

9 Egashira K, Inou T, Hirooka Y, et al. Evidence of impaired endotheliumdependent coronary vasodilatation in patients with angina pectoris and normal coronary angiograms. N Engl J Med 1993;328:1659-64.

10 Jadhav ST, Sattar N, Ferrell WR, et al. Endothelial function is negatively correlated to ST-segment depression during exercise in women with angina and normal coronary arteries [abstract]. Eur Heart J 2002;23:591.

11 Watts GF, O'Brien SF, Silvester W, et al. Impaired endothelium-dependent and independent dilatation of forearm resistance arteries in men with diettreated non-insulin-dependent diabetes: role of dyslipidaemia. Clin Sci (Colch) 1996:91:567-73.

12 Williams SB, Cusco JA, Roddy MA, et al. Impaired nitric oxide-mediated vasodilation in patients with non- insulin-dependent diabetes mellitus. J Am Coll Cardiol 1996;27:567-74.

13 Enderle MD, Benda N, Schmuelling RM, et al. Preserved endothelial function in IDDM patients, but not in NIDDM patients, compared with healthy subjects. Diabetes Care 1998;21:271-7.

14 Caballero AE, Arora S, Saouaf R, et al. Microvascular and macrovascular reactivity is reduced in subjects at risk for type 2 diabetes. Diabetes 1999;48: 1856-62.

15 Balletshofer BM, Rittig K, Enderle MD, et al. Endothelial dysfunction is detectable in young normotensive first- degree relatives of subjects with type 2 diabetes in association with insulin resistance. Circulation 2000;101:1780-4

16 Jaap AJ, Shore AC, Tooke JE. Relationship of insulin resistance to microvascular dysfunction in subjects with fasting hyperglycaemia Diabetologia 1997:40:238-43.

17 Serne EH, Stehouwer CD, ter Maaten JC, et al. Microvascular function relates to insulin sensitivity and blood pressure in normal subjects. Circulation 1999;99:896-902.

18 Dagres N, Saller B, Haude M, et al. Insulin sensitivity relates to coronary microvascular function in non-diabetic subjects with angiographically unobstructed coronary arteries and no to moderate signs of atherosclerosis in intracoronary ultrasound [abstract]. Circulation 2000;102(suppl II): 508-9.

19 Al Suwaidi J, Higano ST, Holmes DR Jr, et al. Obesity is independently associated with coronary endothelial dysfunction in patients with normal or mildly diseased coronary arteries. J Am Coll Cardiol 2001;37:1523-8.

20 Arcaro G, Zamboni M, Rossi L, et al. Body fat distribution predicts the degree of endothelial dysfunction in uncomplicated obesity. Int $J$ Obes Relat Metab Disord 1999;23:936-42.

21 Steinberg HO, Chaker H, Leaming R, et al. Obesity/insulin resistance is associated with endothelial dysfunction. Implications for the syndrome of insulin resistance. J Clin Invest 1996;97:2601-10.

22 Bragulat E, de la SA, Antonio MT, et al. Endothelial dysfunction in saltsensitive essential hypertension. Hypertension 2001;37:444-8

23 Li J, Zhao SP, Li XP, et al. Non-invasive detection of endothelial dysfunction in patients with essential hypertension. Int J Cardiol 1997;61:165-9.

24 Voors AA, Oosterga $M$, Buikema $H$, et al. Dyslipidemia and endotheliumdependent relaxation in internal mammary arteries used for coronary bypass surgery. Cardiovasc Res 1997;34:568-74.

25 Petrie JR, Ueda S, Webb DJ, et al. Endothelial nitric oxide production and insulin sensitivity. A physiological link with implications for pathogenesis of cardiovascular disease. Circulation 1996;93:1331-3.

26 Cleland SJ, Petrie JR, Small M, et al. Insulin action is associated with endothelial function in hypertension and type 2 diabetes. Hypertension 2000;35:507-11.

27 Ueda S, Petrie JR, Cleland SJ, et al. The vasodilating effect of insulin is dependent on local glucose uptake: a double blind, placebo-controlled study. $J$ Clin Endocrinol Metab 1998;83:21 26-31.
28 Vehkavaara S, Makimattila S, Schlenzka A, et al. Insulin therapy improves endothelial function in type 2 diabetes. Arterioscler Thromb Vasc Biol 2000;20:545-50.

29 Zeng G, Nystrom FH, Ravichandran LV, et al. Roles for insulin receptor, $\mathrm{PI} 3$-kinase, and Akt in insulin-signaling pathways related to production of nitric oxide in human vascular endothelial cells. Circulation 2000; 101:1539-45

30 Petrie JR, Salt I, Kelly CJG, et al. Endothelial insulin action and resistance: mechanisms and consequences [abstract]. Diabetologia 2001;44(suppl 1):A11.

31 Cleland SJ, Petrie JR, Ueda S, et al. Insulin as a vascular hormone: implications for the pathophysiology of cardiovascular disease. Clin Exp Pharmacol Physiol 1998;25:175-84.

32 Langes K, Nienaber CA, Volk C, et al. Insulin resistance and hyperlipoproteinemia in microvascular angina: risk factors or pathogenetic link? Coron Artery Dis 1995:6:797-804.

33 Botker HE, Moller N, Ovesen P, et al. Insulin resistance in microvascular angina (syndrome X). Lancet 1993;342:136-40.

34 Godsland IF, Crook D, Stevenson JC, et al. Insulin resistance syndrome in postmenopausal women with cardiological syndrome X. Br Heart J 1995; 74:47-52.

35 Swan JW, Walton C, Godsland IF, et al. Insulin resistance syndrome as a feature of cardiological syndrome $\mathrm{X}$ in non-obese men. $\mathrm{Br}$ Heart $\mathrm{J}$ 1994;71:41-4.

36 Botker $\mathrm{HE}$, Frobert $\mathrm{O}$, Moller N, et al. Insulin resistance in cardiac syndrome $\mathrm{X}$ and variant angina: influence of physical capacity and circulating lipids. Am Heart J 1997;134:229-37

37 Piatti P, Fragasso G, Monti LD, et al. Endothelial and metabolic characteristics of patients with angina and angiographically normal coronary arteries: comparison with subjects with insulin resistance syndrome and normal controls. J Am Coll Cardiol 1999;34:1452-60.

38 Ziccardi P, Nappo F, Giugliano G, et al. Reduction of inflammatory cytokine concentrations and improvement of endothelial functions in obese women after weight loss over one year. Circulation 2002;105:804-9.

39 Mather KJ, Verma S, Anderson TJ. Improved endothelial function with metformin in type 2 diabetes mellitus. J Am Coll Cardiol 2001:37:1344-50.

40 Jadhav ST, Sattar N, Ferrell WR, et al. Effects of metformin on microvascular dysfunction, metabolic parameters and ischaemic measures in women with cardiac syndrome $\mathrm{X}$ : a double-blind randomised placebo-controlled trial [abstract]. Circulation 2003;108:562-3.

41 Verma S, Yao L, Dumont AS, et al. Metformin restores the vascular actions of insulin in hypertension [abstract]. Circulation 2000;102(suppl II):608.

42 Zhou G, Myers R, Li Y, et al. Role of AMP-activated protein kinase in mechanism of metformin action. J Clin Invest 2001;108:1167-74.

43 Fryer LG, Hajduch E, Rencurel F, et al. Activation of glucose transport by AMP-activated protein kinase via stimulation of nitric oxide synthase. Diabetes 2000; 49:1978-85.

44 Fontbonne A, Charles MA, Juhan-Vague I, et al. The effect of metformin on the metabolic abnormalities associated with upper-body fat distribution. BIGPRO study group. Diabetes Care 1996;19:920-6.

45 Kelly IE, Han TS, Walsh K, et al. Effects of a thiazolidinedione compound on body fat and fat distribution of patients with type 2 diabetes. Diabetes Care 1999;22:288-93.

46 Watanabe Y, Sunayama S, Shimada K, et al. Troglitazone improves endothelial dysfunction in patients with insulin resistance. J Atheroscler Thromb 2000;7:159-63.

47 Murakami T, Mizuno S. Effects of thiazolodinedione on effort induced angina pectoris with type-2 diabetes mellitus [abstract]. Circulation 2000;102(suppl II):706-7.

48 Pampaloni MH, Hsueh WA, Quinones M, et al. Beneficial effects of insulin sensitisers on coronary endothelial function in insulin resistant non-diabetic patients by noninvasive measurements of myocardial blood low [abstract]. Circulation 2000; (suppl II).

49 Walker AB, Chattington PD, Buckingham RE, et al. The thiazolidinedione rosiglitazone (BRL-49653) lowers blood pressure and protects against impairment of endothelial function in Zucker fatty rats. Diabetes 1999:48:1448-53.

50 Tack $\mathrm{CJ}$, Ong MK, Lutterman JA, et al. Insulin-induced vasodilatation and endothelial function in obesity/insulin resistance. Effects of troglitazone. Diabetologia 1998;41:569-76.

51 Murakami T, Mizuno S, Ohsato K, et al. Effects of troglitazone on frequency of coronary vasospastic-induced angina pectoris in patients with diabetes mellitus. Am J Cardiol 1999;84:92-4, A8.

52 Shimabukuro M, Shinzato T, Higa S, et al. Enhanced insulin response relates to acetylcholine-induced vasoconstriction in vasospastic angina. J Am Coll Cardiol 1995;25:356-61

53 Sgambato $S$, Varricchio $M$, Tesauro $P$, et al. The use of metformin in ischemic cardiopathy. Clin Ter 1980;94:77-85. 